\title{
Abnormal Skeletal Growth Patterns in Adolescent Idiopathic Scoliosis
}

\author{
Type of article: Original Article
}

\author{
Houria Kaced ${ }^{a}$, Hanène Belabbassia, Assia Haddouche ${ }^{b}$. \\ ${ }^{a}$ Department of Physical Medicine and Rehabilitation, University Hospital, DjillaliBounaama, Rue des \\ frères halim, Douera, Algiers. Blida1 University, Faculty of Medicine, BP 270 Route de Soumaa, \\ Blida, Algeria. \\ ${ }^{b}$ Department of Rhumatology, Blida Public Hospital, Avenue KritliMokhtar, Blida. Blida1 University, \\ Faculty of Medicine, BP 270 Route de Soumaa, Blida, Algeria. \\ h_kaced@univ-blida.dz
}

\begin{abstract}
Background: Adolescent Idiopathic Scoliosis (AIS) occurs among children during their pubertal growth spurt. Although there is no clear consensus on the difference in body height between AIS and healthy controls, it is generally thought that the development and curve progression in patients with AIS is closely associated with their growth rate.

Our aim is to compare the anthropometric parameters of children with AIS and those of a control group within different age groups ranging from 9 to 16 years old.

Methods: It is a prospective, cross-sectional, case-control study which include 431children, 258 girls, 110 with AIS and 148 healthy controls, whereas in the group of males 173, 49 have AIS and 124 don't have deformity.

Anthropometric parameters, clinical examination of the trunk and radiological assessment of the spine are records. The statistical analysis is performed using SPSS package.

Children are examined from a school-screening program in our physical medicine department in the university hospital of Douera in Algiers. Measurements are assessed, including anthropometric parameters (body height, body weight, secondary sexual characters using Tanner stage, puberty age), trunk asymmetry and Cobb angle of scoliosis.

Results: Girls with AIS are generally taller, with a higher weight than the healthy controls with a significant difference at the age of 12 years old. Otherwise, boys with AIS aged of 14 years are significantly taller than their controls.

Conclusion: The growth patterns in terms of tallness with AIS are significantly different from healthy controls at the ages of 12 for girls and 14 for boys.

Key words: scoliosis, screening, bone growth, body height, body weight

Corresponding author: Dr Houria Kaced, Department of Physical Medicine and Rehabilitation, University Hospital,

DjillaliBounaama, Rue des frères halim, Douera, Algiers. Blida1 University, Faculty of Medicine, BP 270 Route de Soumaa, Blida,

Algeria. Email: h_kaced@univ-blida.dz

Received: June 15, 2017, Accepted: October 30, 2017, English editing: November 27, 2017, Published: November 28, 2017.

Screened by iThenticate. $\odot 2017$ KNOWLEDGE KINGDOM PUBLISHING.
\end{abstract}

\section{Introduction}

AIS is known to be a three-dimensional spine deformity with unknown pathogenesis, progression may occur until the end of bone maturity in $10 \%$ to $20 \%$ [10, 16, 22] of curves detected in school screening programs and not treated. Factors that correlate with the risk of curve progression have been identified in natural history studies of AIS, as sex, curves pattern, Cobb angle, age at diagnosis, menarche and Risser sign [2, 4, 6, 18, 19, 21].

Many authors recognized that the development and progression of idiopathic scoliosis are growth related and they reported that the curve progression occurs during the adolescent growth spurt both in females and males $[6,8,9,12,17,23]$. More knowledge about this 
spine deformity revealed that the pubertal development and curve progression in patients with AIS are closely associated with their growth rate $[1,6,7,13,20]$, as well as body growth seems to be different between healthy children and those with idiopathic scoliosis. This correlation between growth and AIS was illustrated by the Duval-Beaupère diagram (Fig.1) [8] which shows curves progression increasing and coinciding with growth spurt during the peri-pubertal period, where height velocity is the greatest at pubertal stages II and III of Tanner classification [8, 17].

Classically, slowed aggravation continues until Risser 3-4 in girls and later in boys at Risser5.

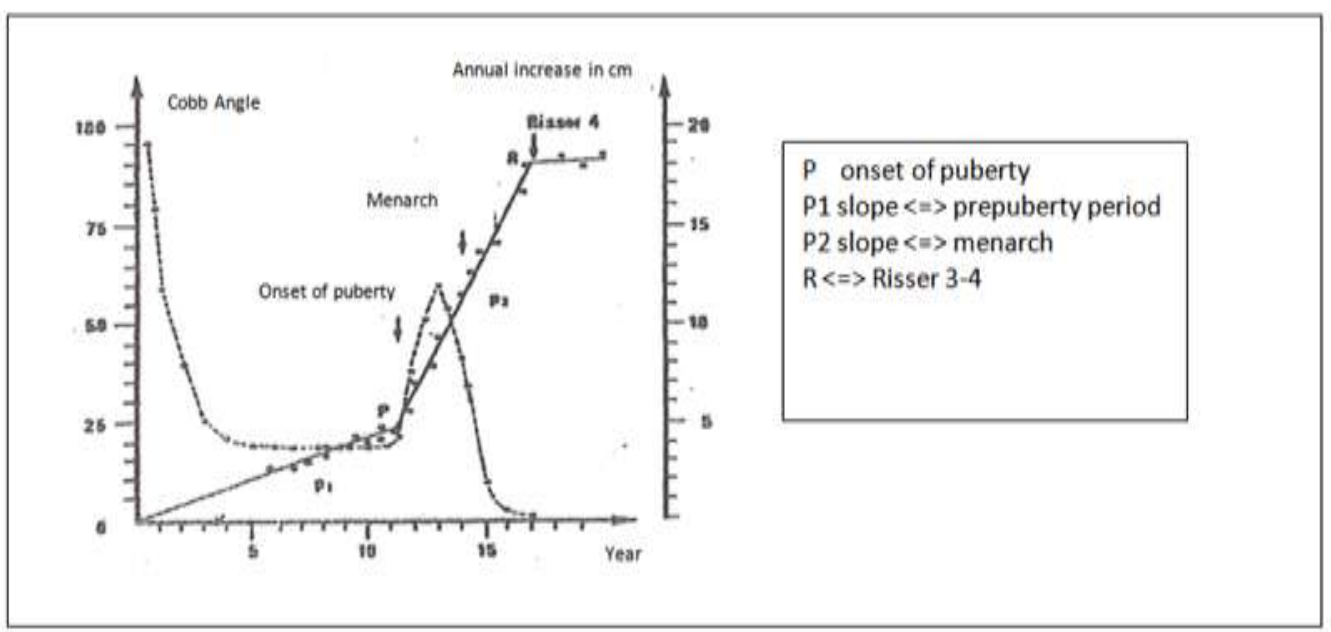

Fig 1: Duval-Beaupère diagram [8] (translated from French to English).

This study aimed at comparing the anthropometric parameters of children with adolescent idiopathic scoliosis (AIS) and those of a control group with children age.

\section{Material and Methods}

We proceeded to a prospective study on the anthropometric parameters of children with adolescent idiopathic scoliosis(AIS), using cross-sectional and case-control data set in comparison with children age. We performed this study within a school screening program managed during a 2-year period between 2011 and 2012 at the department of physical medicine and rehabilitation in Algiers, Algeria.

The inclusion criteria for patients were age and Cobb angle. School children with ages ranging from 9 to 16 years were selected as it was recommended in a study made in Algiers during 1995 and 1996 [11]. Patients screened were considered having scoliosis, when the Cobb angle measured $10^{\circ}$ or more. For the control group we selected subjects without scoliosis that were of similar age. Consent was obtained from all the parents before admission to the study. Excluded were patients with evidence of abnormalities, thoracic deformity, congenital spine abnormalities, skeletal dysplasia, neuromuscular diseases and other types of scoliosis.

Different anthropometric parameters were assessed, using standard procedures. Standing height was measured with the subjects standing upright against a wall- mounted stadiometer, with their heads positioned in the Frankfort horizontal plane and their heels against this tool. 
Medical Technologies Journal, Volume: 1, Issue: 4, October-December 2017, Pages:80-90. Doi : https://doi.org/10.26415/2572-004X-vol1iss4p80-90

Corrected height was calculated using Bjure equation: $\log \mathrm{y}=0.011 \mathrm{x}-0.177[3,14,25]$, where $\mathrm{y}$ is the reduction in trunk height $(\mathrm{cm})$ caused by the spinal deformity, and $\mathrm{x}$, the Cobb angle of the primary curve.

Body Weight $(\mathrm{Kg})$ was measured in light clothes without shoes on a standard weighing scale.

Body Mass Index was calculated considering the corrected height in scoliotic school children.

Puberty was appreciated on Secondary Sexual Characters using Tanner's method [17] and menarche which age was 12.53 years for girls with AIS and 12.97 for those without AIS. The difference was statistically not significant. The period of changing (breaking) of voice was difficult to be known in boys.

The diagnosis of AIS was confirmed on a clinical examination using Adam's forward bending test $[5,11,25]$, and a standard standing radiograph of the Spine. The Adams test was done in ambient temperature, on undressed child. The child bends at the hips to nearly $90^{\circ}$ forward, with the arms relaxed, palms together hand in front of the other, the knees straight, hind foot joint together and forefoot making $30^{\circ}$. The physician inspects the trunk from a posterior to anterior view, and notes any asymmetrical prominence on one side of the thoracic or lumbar area, using a scoliometer.

Before this test was performed, we eliminated any pelvic tilt due to leg length inequality. All children with trunk asymmetry received an X-ray of the spine to confirm the diagnosis of scoliosis which is defined by Cobb angle equal to $10^{\circ}$ or more.

\section{Results}

We used the Statistical Package for the Social Sciences software (SPSS Version 20.0) to calculate the Student's t-test to compare two means. The cut off mark of our level of significance is set to alpha equal to $5 \%$.

Forty hundred and thirty-one (431) school children aged 9 to 16 years old were examined with a predominance of girls $(59.86 \%) .36 .9 \%$ of the total presented the spinal deformity. The distribution of AIS patients and their controls according to their chronological ages is shown in the following graph (Fig. 2) where we see that the girl's sample is randomly distributed but not homogeneously. 
Medical Technologies Journal, Volume: 1, Issue: 4, October-December 2017, Pages:80-90. Doi : https://doi.org/10.26415/2572-004X-vol1iss4p80-90

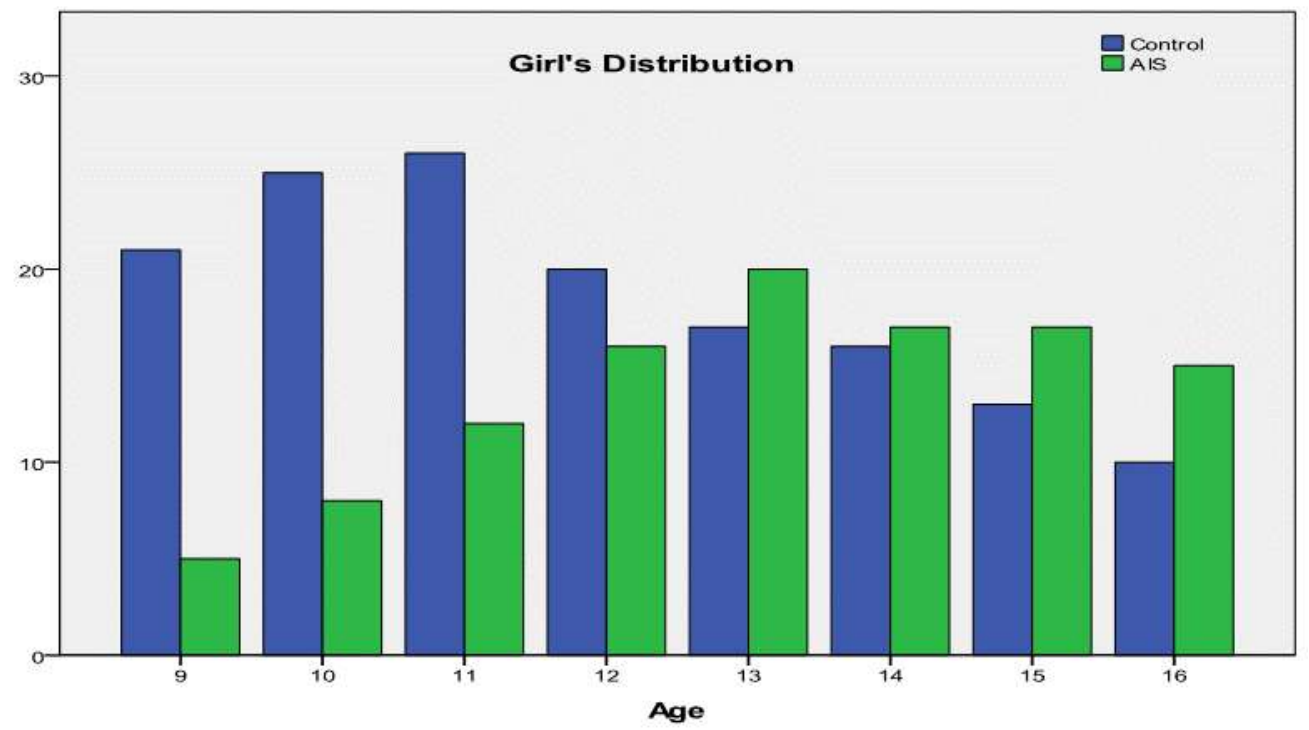

Fig.2: Comparison of girl's distribution between AIS and normal control sample.

That was different in boy's population where the distribution was uniformly homogeneous (Fig.3)

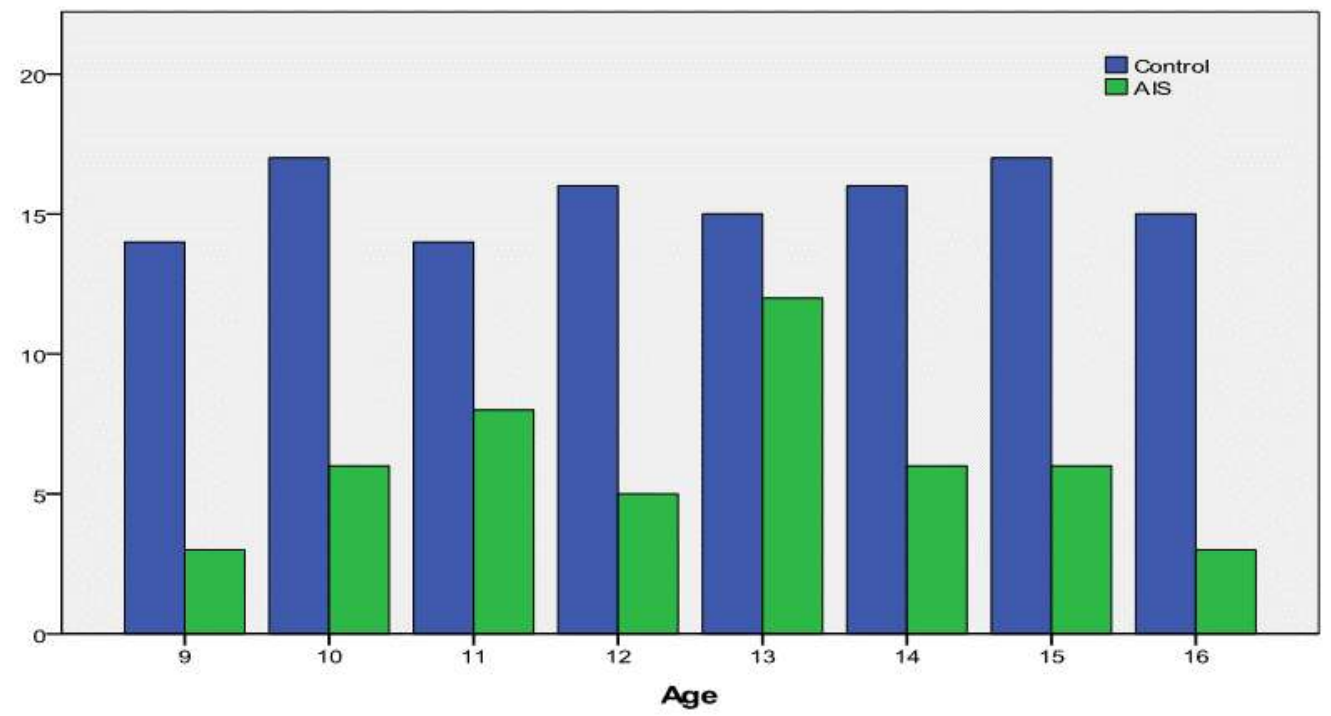

Fig.3: Comparison of boy's distribution between AIS and normal control sample.

\section{Anthropometric Measurements, Girls}

The Body heights, corrected heights, weights of girls with AIS and their healthy controls are illustrated in the following graphs, respectively (Fig.4, 5, 6 and 7). 
Medical Technologies Journal, Volume: 1, Issue: 4, October-December 2017, Pages:80-90. Doi : https://doi.org/10.26415/2572-004X-vol1iss4p80-90

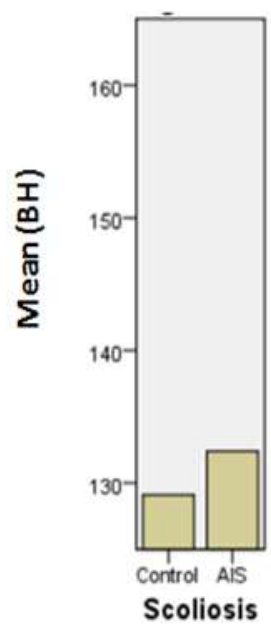

9

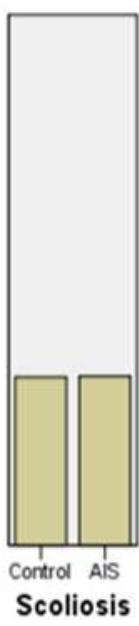

10

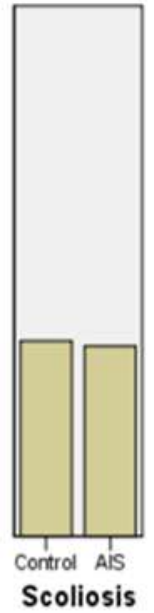

11

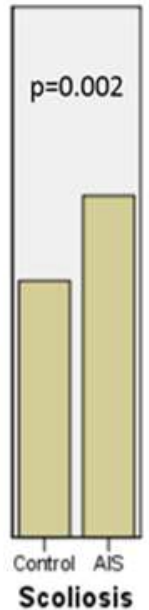

12

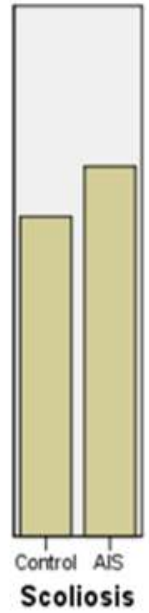

13

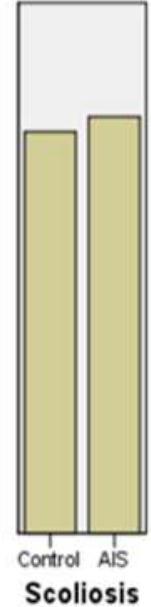

14

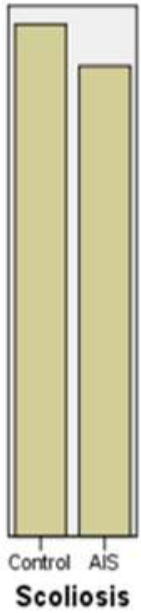

15

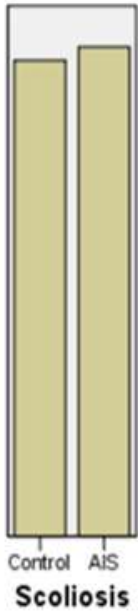

16

Fig.4: Comparison of uncorrected height between the controls and AIS by chronological age in girls
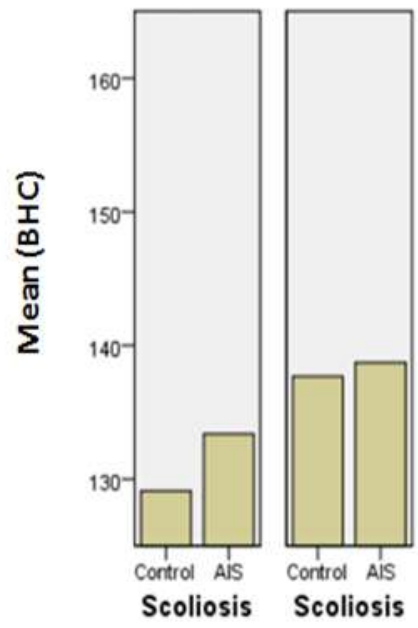

9

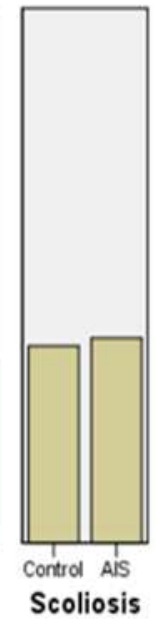

11

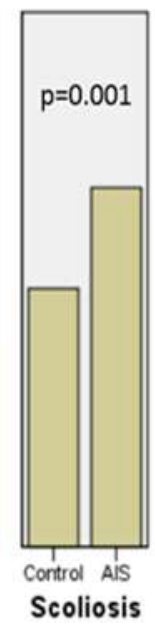

12

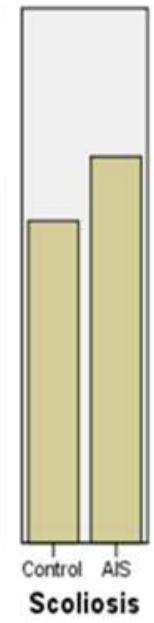

13

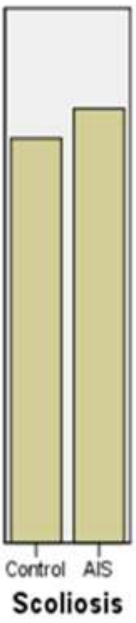

14

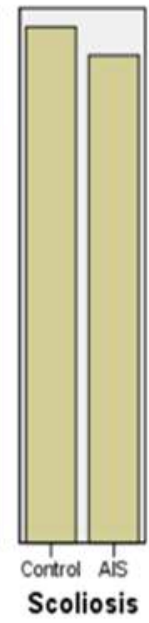

15

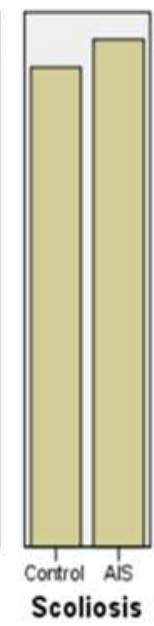

16

Fig.5: Comparison of corrected height between the controls and AIS by chronological age in girls.

Girls with AIS were generally taller than the healthy controls, considering uncorrected height ( $\mathrm{p}=0,002)$ and corrected body height $(\mathrm{p}=0,001)$; height velocity was the greatest at the age 12 which corresponded to the stages II and III of breast and pubic hair development (Tanner's method). 


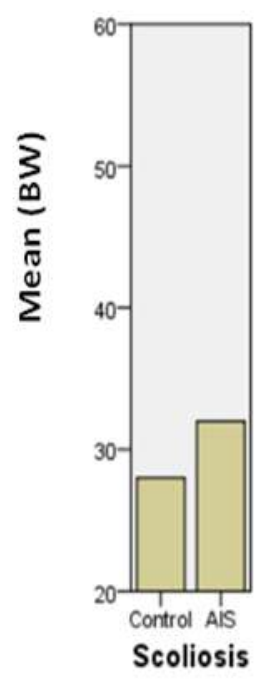

9

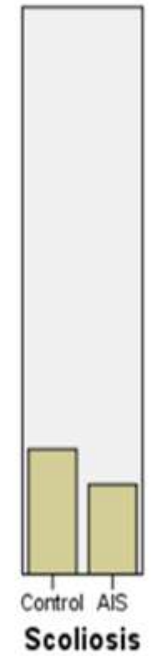

10

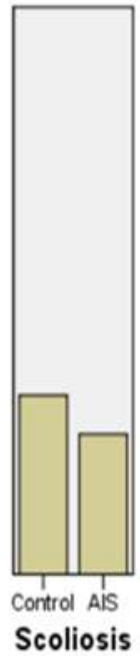

11

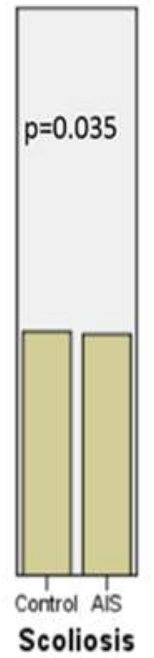

12

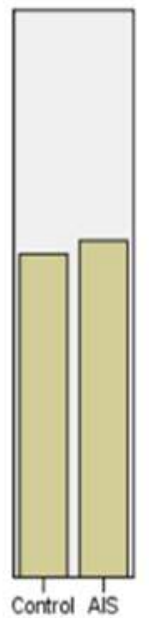

Scoliosis

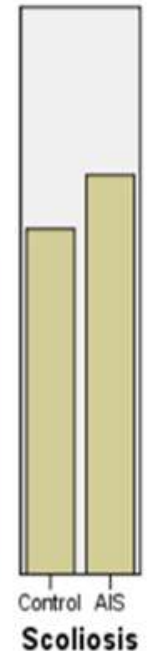

14

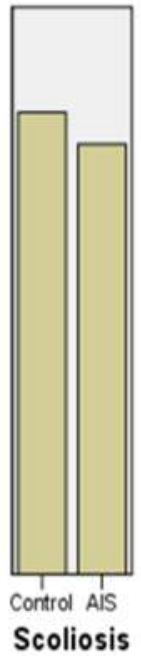

15

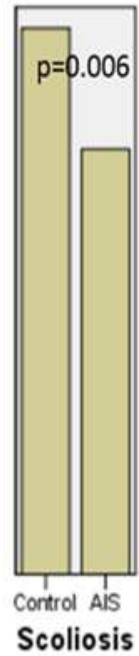

16

Fig.6. Comparisons of body weight between controls and AIS by chronological age in girls.

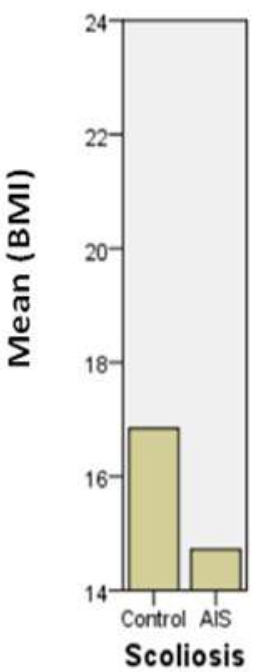

9

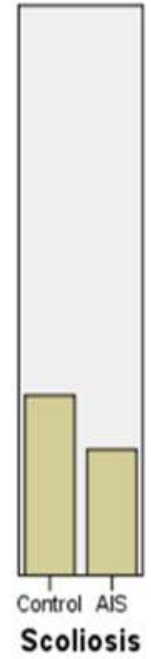

10

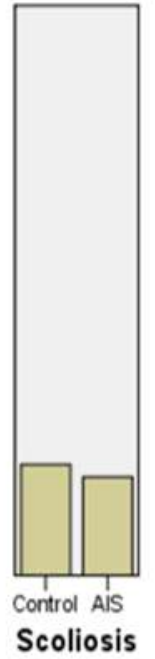

11

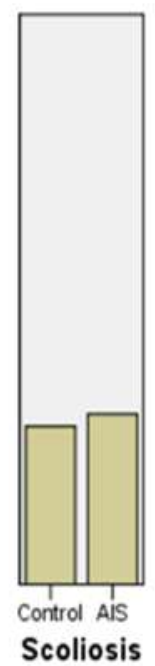

12

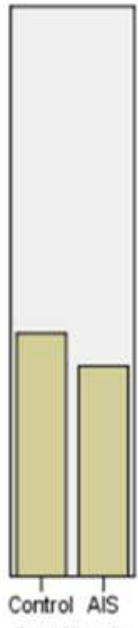

Scoliosis

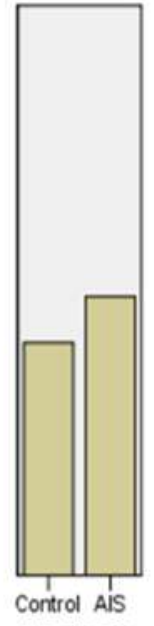

Scoliosis

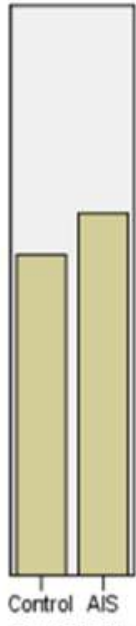

Scoliosis

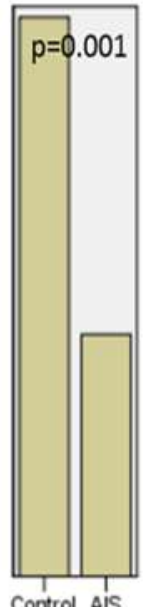

Scoliosis

14

15

16

Fig.7. Comparison of BMI between the controls and AIS by chronological age in girls.

Body weight is higher in AIS than the controls at the onset of puberty with a significant difference, but at an age of 16 years they become underweight. As we see BMI is significantly different with $\mathrm{p}=0.001$. 
Medical Technologies Journal, Volume: 1, Issue: 4, October-December 2017, Pages:80-90. Doi : https://doi.org/10.26415/2572-004X-vol1iss4p80-90

All data obtained in girls are summarized in table 1

Table 1: Comparison of anthropometric measurements between female AIS and their controls by chronological age

\begin{tabular}{|c|c|c|c|c|c|c|c|c|c|c|c|c|}
\hline \multirow{2}{*}{$\begin{array}{l}\text { Age } \\
\text { (yrs) }\end{array}$} & \multicolumn{3}{|c|}{$\mathrm{BH}$} & \multicolumn{3}{|c|}{$\mathrm{CBH}$} & \multicolumn{3}{|c|}{ BW } & \multicolumn{3}{|c|}{ BMI } \\
\hline & AIS & Control & $\mathrm{p}$ & AIS & Control & $\mathrm{p}$ & AIS & Control & $\mathrm{p}$ & AIS & Control & $\mathrm{p}$ \\
\hline 9 & $132 \pm 9$ & $129 \pm 3$ & 0.458 & $133 \pm 3$ & $129 \pm 9$ & 0.338 & $26 \pm 3$ & $28 \pm 8$ & 0.562 & $15 \pm 1$ & $17 \pm 3$ & 0.161 \\
\hline 10 & $138 \pm 6$ & $138 \pm 11$ & 0.982 & $139 \pm 11$ & $138 \pm 6$ & 0.736 & $31 \pm 7$ & $33 \pm 7$ & 0.663 & $16 \pm 2$ & $17 \pm 3$ & 0.377 \\
\hline 11 & $139 \pm 10$ & $140 \pm 10$ & 0.907 & $140 \pm 10$ & $140 \pm 10$ & 0.859 & $31 \pm 6$ & $31 \pm 6$ & 0.961 & $16 \pm 2$ & $16 \pm 2$ & 0.768 \\
\hline 12 & $151 \pm 5$ & $144 \pm 6$ & 0.002 & $152 \pm 7$ & $144 \pm 5$ & 0.001 & $39 \pm 8$ & $35 \pm 4$ & 0.035 & $17 \pm 2$ & $17 \pm 2$ & 0.744 \\
\hline 13 & $153 \pm 10$ & $149 \pm 7$ & 0.205 & $154 \pm 7$ & $149 \pm 10$ & 0.111 & $42 \pm 8$ & $41 \pm 9$ & 0.661 & $18 \pm 2$ & $18 \pm 3$ & 0.547 \\
\hline 14 & $156 \pm 7$ & $155 \pm 7$ & 0.629 & $158 \pm 7$ & $155 \pm 7$ & 0.343 & $47 \pm 9$ & $44 \pm 7$ & 0.263 & $19 \pm 3$ & $18 \pm 2$ & 0.385 \\
\hline 15 & $160 \pm 6$ & $164 \pm 7$ & 0.205 & $161 \pm 7$ & $164 \pm 6$ & 0.388 & $53 \pm 9$ & $53 \pm 8$ & 0.915 & $20 \pm 4$ & $20 \pm 3$ & 0.557 \\
\hline 16 & $162 \pm 5$ & $161 \pm 5$ & 0.635 & $163 \pm 5$ & $161 \pm 5$ & 0.331 & $49 \pm 7$ & $62 \pm 15$ & 0.006 & $18 \pm 2$ & $24 \pm 5$ & 0.001 \\
\hline
\end{tabular}

\section{Anthropometric measurements, boys}

The following graphs $(8,9,10$ and11) illustrate the anthropometric measurements in boys.
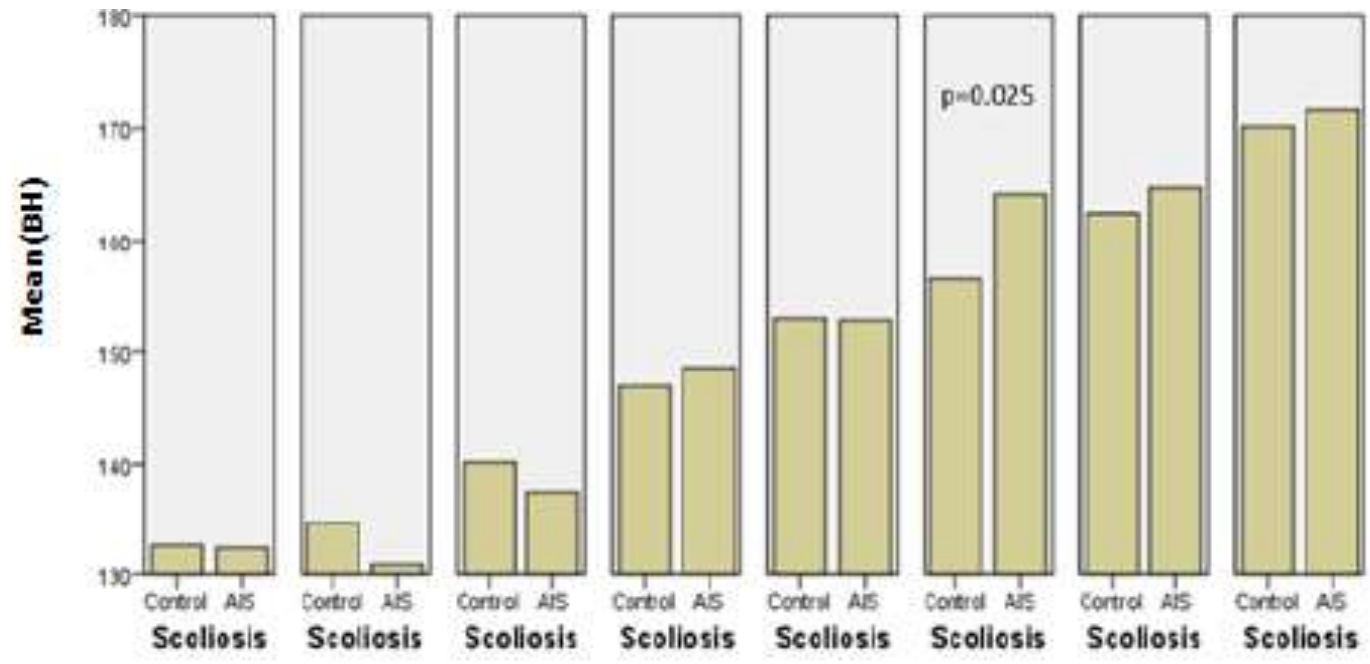

9

10
11
14

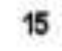

16
12

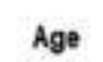

13

Fig.8: Comparison of height between the controls and AIS by chronological age in boys. 
Medical Technologies Journal, Volume: 1, Issue: 4, October-December 2017, Pages:80-90. Doi : https://doi.org/10.26415/2572-004X-vol1iss4p80-90
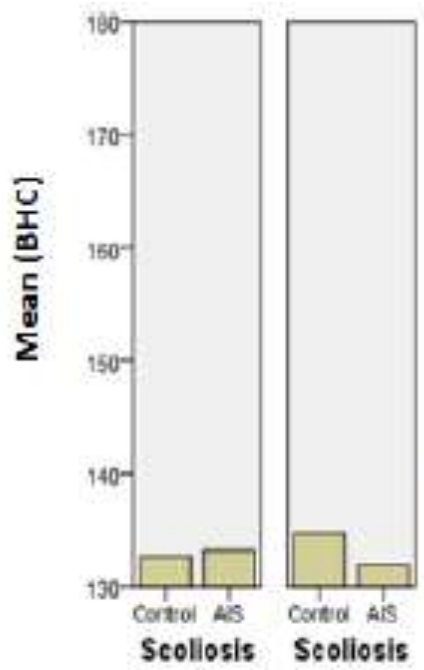

9

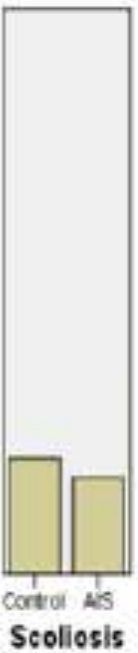

11

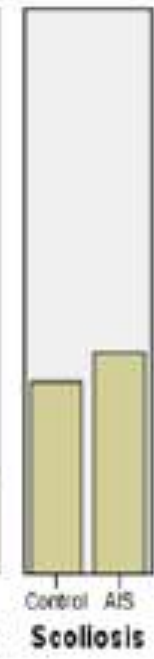

12

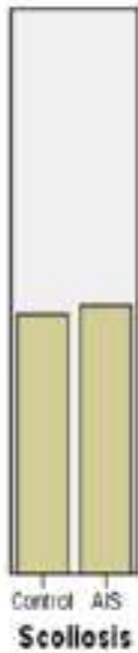

13

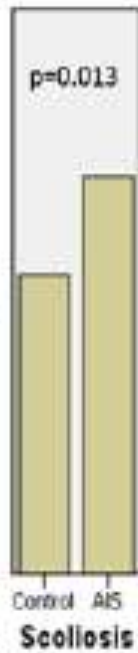

14

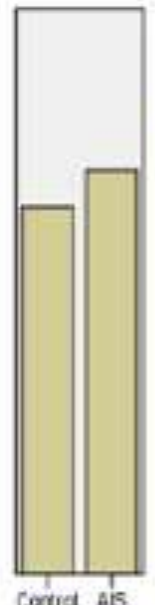

Scoliosis

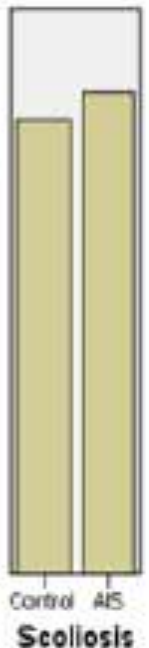

15

16

Fig.9: Comparison of corrected height between the controls and AIS by chronological age in boys In terms of weight, we noticed that the BMI is higher at the age of 9 in AIS group with $\mathrm{p}=0.042$.

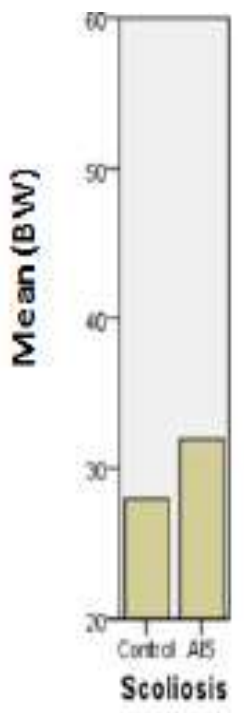

9

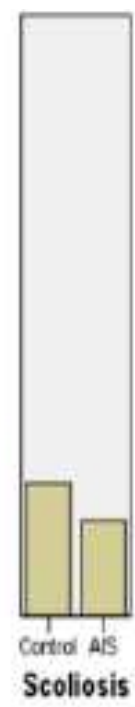

10

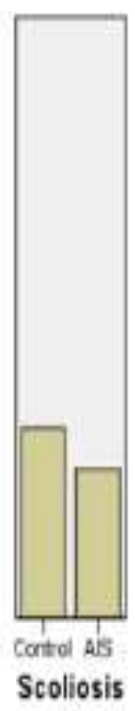

11

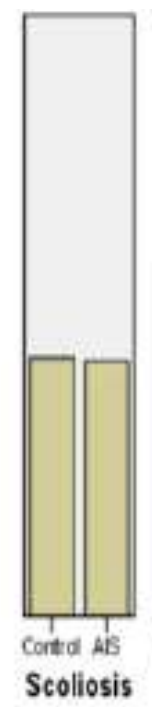

12

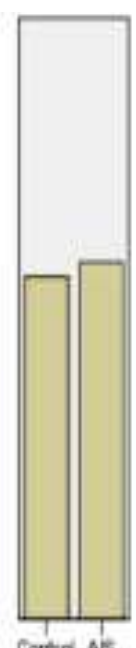

Scoliosis

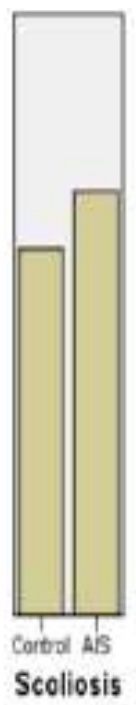

14

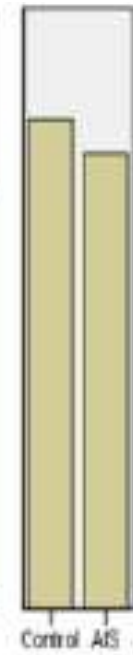

Scoliosis

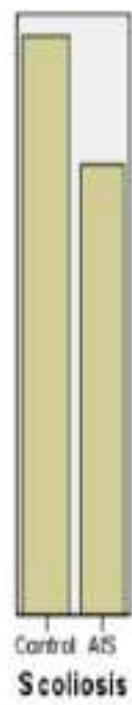

15

16

Fig.10: Comparisons of body weight between the controls and AIS by chronological age in boys. 
Medical Technologies Journal, Volume: 1, Issue: 4, October-December 2017, Pages:80-90. Doi : https://doi.org/10.26415/2572-004X-vol1iss4p80-90
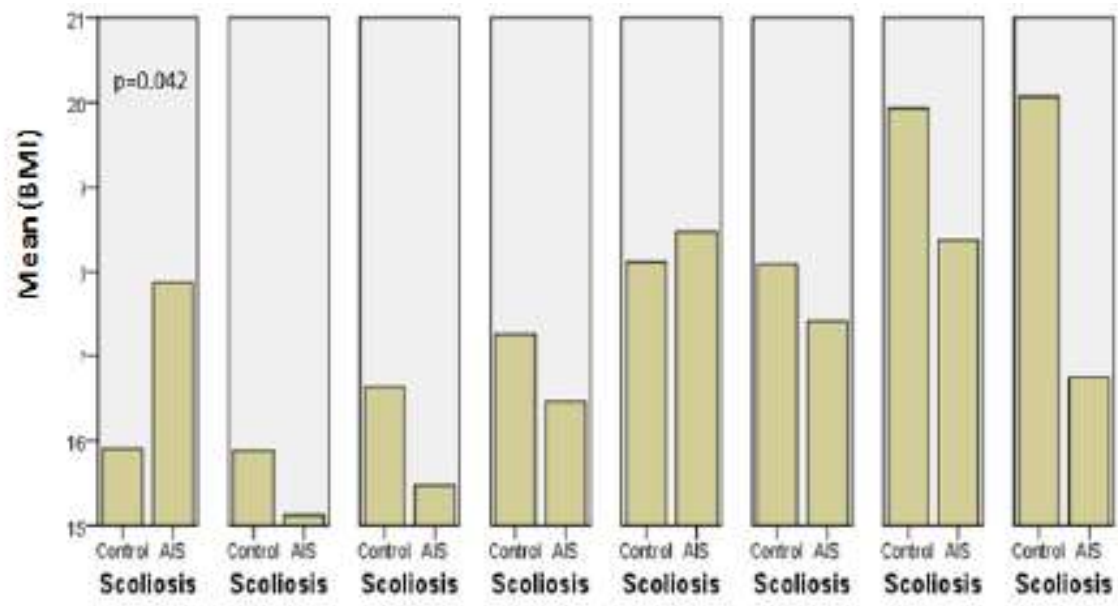

9

10

11

12

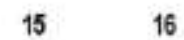

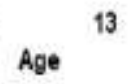

Fig. 11: Comparisons of BMI between the controls and AIS by chronological age in boys.

All data obtained in boys are summarized in table 2

Table2: Comparison of anthropometric measurements between male AIS and their controls by chronological age.

\begin{tabular}{|c|c|c|c|c|c|c|c|c|c|c|c|c|}
\hline \multirow{2}{*}{$\begin{array}{l}\text { Age } \\
\text { (yrs) }\end{array}$} & \multicolumn{3}{|c|}{$\mathrm{BH}$} & \multicolumn{3}{|c|}{$\mathrm{CBH}$} & \multicolumn{3}{|c|}{ BW } & \multicolumn{3}{|c|}{ BMI } \\
\hline & AIS & $\begin{array}{c}\text { Contro } \\
1\end{array}$ & $\mathrm{P}$ & AIS & $\begin{array}{c}\text { Contro } \\
1\end{array}$ & $\mathrm{p}$ & AIS & $\begin{array}{c}\text { Contro } \\
1\end{array}$ & $\mathrm{p}$ & AIS & $\begin{array}{c}\text { Contro } \\
1\end{array}$ & $\mathrm{P}$ \\
\hline 9 & $132 \pm 7$ & $133 \pm 4$ & 0.935 & $133 \pm 7$ & $133 \pm 4$ & 0.828 & $32 \pm 7$ & $28 \pm 3$ & 0.107 & $18 \pm 2$ & $16 \pm 1$ & 0.042 \\
\hline 10 & $131 \pm 6$ & $135 \pm 4$ & 0.104 & $132 \pm 6$ & $135 \pm 4$ & 0.222 & $26 \pm 3$ & $29 \pm 3$ & 0.079 & $15 \pm 1$ & $16 \pm 1$ & 0.182 \\
\hline 11 & $\begin{array}{c}138 \pm 1 \\
1\end{array}$ & $140 \pm 6$ & 0.482 & $\begin{array}{c}138 \pm 1 \\
1\end{array}$ & $140 \pm 6$ & 0.655 & $30 \pm 5$ & $33 \pm 4$ & 0.205 & $15 \pm 1$ & $17 \pm 2$ & 0.178 \\
\hline 12 & $149 \pm 6$ & $147 \pm 4$ & 0.537 & $150 \pm 6$ & $147 \pm 4$ & 0.301 & $37 \pm 6$ & $37 \pm 7$ & 0.957 & $16 \pm 2$ & $17 \pm 3$ & 0.624 \\
\hline 13 & $\begin{array}{c}153 \pm 1 \\
0\end{array}$ & $\begin{array}{c}153 \pm 1 \\
2\end{array}$ & 0.973 & $\begin{array}{c}154 \pm 1 \\
0\end{array}$ & $\begin{array}{c}153 \pm 1 \\
2\end{array}$ & 0.852 & $44 \pm 9$ & $43 \pm 10$ & 0.808 & $18 \pm 4$ & $18 \pm 3$ & 0.782 \\
\hline 14 & $164 \pm 9$ & $156 \pm 6$ & 0.025 & $165 \pm 9$ & $156 \pm 6$ & 0.013 & $\begin{array}{c}48 \pm 1 \\
2\end{array}$ & $44 \pm 7$ & 0.349 & $17 \pm 2$ & $18 \pm 2$ & 0.553 \\
\hline 15 & $\begin{array}{c}165 \pm 1 \\
0\end{array}$ & $162 \pm 8$ & 0.577 & $\begin{array}{c}166 \pm 1 \\
0\end{array}$ & $162 \pm 8$ & 0.436 & $50 \pm 6$ & $53 \pm 10$ & 0.607 & $18 \pm 2$ & $20 \pm 4$ & 0.317 \\
\hline 16 & $172 \pm 8$ & $170 \pm 7$ & 0.736 & $173 \pm 8$ & $170 \pm 7$ & 0.589 & $50 \pm 6$ & $59 \pm 13$ & 0.288 & $17 \pm 1$ & $20 \pm 3$ & 0.131 \\
\hline
\end{tabular}

\section{Discussion}

Abnormal growth was observed in the natural history of AIS during puberty as it has been reported in many important studies [4, 6, 20, 23], which described more disorders in girls. In the present study, the results demonstrate that the girls with AIS are generally taller than the healthy controls, considering uncorrected and corrected height, the difference is significant at the age of 12 .

In the literature, Cheng and al [5] didn't find any statistical difference neither in uncorrected height nor in uncorrected sitting height between AIS girls and normal controls 
at each age group except for the age of 15, however, after corrected trunk loss, girls with the spine deformity were significantly taller than the controls between ages 13 and 15 .Yim and al [25] compared anthropometric parameters with severity of the curves and concluded that, the uncorrected height was the same for each group of age and the corrected height in AIS group with a Cobb angle greater than $40^{\circ}$ was shorter than the matched control at the age of 12 , it subsequently caught up and became significantly taller than the control group at the age of 14 to 16 years old

After analysis of data of weight, we see that girls with AIS are underweight at an age of 16 , and BMI was significantly lower with $\mathrm{p}=0.001$. Certain authors $[5,25]$ reported that weight and BMI were lower in AIS than in controls, for Yim and all other authors, it was significantly lower in the AIS20 and AIS40 groups across all ages except for the age of 15 years.

Concerning boys, corrected and uncorrected heights are significantly higher than matched controls at age of 14, while Wang who studied arm spans and corrected standing heights showed that these measurements were similar, in most of the ages [18].

Analysis of weights and BMI didn't give us objective difference between boys with AIS and the matched controls, even males seem to be underweight at the end of maturity in the small sample of ours. When we compare these results to the literature, we find that in a series larger than in our study, Wang [18] demonstrated that male AIS presented lower body weights and BMIs than their controls, between the ages of 15 and 17, with a significant difference.

The present investigation, the first one in our country, aimed to compare the anthropometric measurements between children with AIS and a healthy control group of similar age during the peri-pubertal period in a small-scale cross-sectional study of a school population sample.

Obviously, girls and boys with AIS exhibit abnormal longitudinal growth. More than this we noticed in our empirical practice, that boys and girls lost weight at the end of growth, but we can't prove that. Indeed, we did not research about the possible causes as genetic status, eating behavior, practicing sport, factors that could influence growth.

We believe that, in addition to the anthropometric parameters which are important maturity indicators that reflect growth and can predict the progression of scoliosis curvatures, we must consider other signs such as sexual characters, skeletal maturity (Risser sign, bone age) and morphology of proper vertebral deformity especially in the sagittal plane that can contribute to understand the worsening scoliosis.

More investigation and more research in the field of spinal deformities will probably reveal that their progression in children and adolescents depends on a set of known and less known factors, and may be will highlight the relation between at last three elements as growth, genetics and nutritional status.

\section{Conflict of interest statement}

We certify that there is no conflict of interest with any financial organization in the subject matter or materials discussed in this manuscript.

\section{Authors' biography}

No biography 
Medical Technologies Journal, Volume: 1, Issue: 4, October-December 2017, Pages:80-90. Doi : https://doi.org/10.26415/2572-004X-vol1iss4p80-90

\section{References}

1. Busscher I; Wapstra FH; Veldhuizen AG. Predicting growth and curve progression in the individual patient with adolescent idiopathic scoliosis: design of a prospective longitudinal cohort study.BMC Musculoskeletal Disorders [BMC MusculoskeletDisord] 2010 May 17; Vol. 11, pp. 93. https://doi.org/10.1186/1471-2474-11-93 PMid:20478013 PMCid:PMC2881883

2. Biondi J, Weiner DS, Bethem D, Reed JF 3rd (1985) Correlation of Risser sign and bone age determination in adolescent idiopathic scoliosis. J PediatrOrthop 5:697-701 https://doi.org/10.1097/01241398-198511000-00013 PMid:4066945

3. Bjure J, Nachemson A (1973) Non-treated scoliosis. ClinOrthop Relat Res 93:44-52. https://doi.org/10.1097/00003086-197306000-00007 PMid:4579097

4. Bunnel W.P. The natural history of idiopathic scoliosis before skeletal maturity. Spine 1986; 11 (8): 773-6 https://doi.org/10.1097/00007632-198610000-00003

5. Cheng JC, Leung SS, Lau J (1996) Anthropometric measurements and body proportions among Chinese children. ClinOrthop. Relat Res 323:22-30 https://doi.org/10.1097/00003086-199602000-00004 PMid:8625584

6. Duval-Beaupère G. Pathogenic relationship between scoliosis and growth. Scoliosis and growth. Sorab, Livingstone, Edinbourg and London, 1971, 58.

7. Duval-Beaupère G., Barthel. F. La croissance des scoliotiques. Rev.Chr.Orthop. 1983; 69: 201-206

8. Duval-BeaupèreG . Les lois d'évolutivité des scolioses. Application pratique. Réunion conjointe GES et SRSQ. Montréal, 1979.

9. Goldberg CJ, Fogarty EE, Moore DP, Dowling FE (1997) Scoliosis and developmental theory: adolescent idiopathic scoliosis. Spine (Phila Pa 1976) 22:2228-2237 discussion 2237-2228

https://doi.org/10.1097/00007632-199710010-00006

10. Guillaumat.M. Lebard J.P., Khoury N., Tassin J.L. Scoliose idiopathique en période de croissance.

Encycl.Med.Chir (Paris-France). AppareilLocomoteur, 15874 A10, 1991.

11. Kaced, H. Belabbassi, H. School Screening for Scoliosis in Algiers. Results of a survey conducted in 1995 1996. SOSORT 20-23 May, 2009; Lyon, France

12. Lonstein J.E. Natural history and School Screening for Scoliosis. OrthopClin North Am 1988; 19: 227-37. PMid:3282198

13. Nachemson A. Etiology and Natural History of Scoliosis. 1st European Congress on Scoliosis and Kyphosis. Dubrovnik 1983

14. Sanders JO, Browne RH, Cooney TE, Finegold DN, McConnellSJ, Margraf SA (2006) Correlates of the peak height velocity in girls with idiopathic scoliosis. Spine (Phila Pa 1976) 31: 2289-2295

https://doi.org/10.1097/01.brs.0000236844.41595.26 PMid:16985455

15. Siu King Cheung C, Tak Keung Lee W, Kit Tse Y, Ping Tang S, Man Lee K, Guo X, Qin L, Chun Yiu Cheng J (2003) Abnormalperi-pubertal anthropometric measurements and growth pattern in adolescent idiopathic scoliosis: a study of 598 patients. Spine (Phila Pa 1976) 28:2152-2157

https://doi.org/10.1097/01.BRS.0000084265.15201.D5 PMid:14501928

16. Subileau. La Scoliose, Dépistage Précoce. Journée du 2-10-1982. La Baule, France.

17. Tanner J.M. Growth at Adolescence. Blackwell Scientific Publications, ed., Oxford, $2^{\circ}$ ed., 1962

18. Wang Wei-Jun • Sun Xu • Wang Zhi-Wei, QiuXu-sheng • Liu Zhen • Qiu Yong. Abnormal anthropometric measurements and growth pattern in male adolescent idiopathic scoliosis Eur. Spine J. (2012) 21:77-83

https://doi.org/10.1007/s00586-011-1960-x PMid:21826498 PMCid:PMC3252435

19. Weinstein SL, Ponseti IV (1983) Curve progression in idiopathic scoliosis. J Bone JtSurg Am 65:447-455 https://doi.org/10.2106/00004623-198365040-00004

20. Weinstein S.L. Idiopathic Scoliosis. Natural history. Spine 1986; 11 (8): 780 - 783.

https://doi.org/10.1097/00007632-198610000-00006

21. Willner S (1974) Growth in height of children with scoliosis. ActaOrthopScand 45:854-866 https://doi.org/10.3109/17453677408989696

22. Winter R.B. Adolescent IdiopathicScoliosis. N. Engl. J. Med.314, 1379 - 1380.

https://doi.org/10.1056/NEJM198605223142108 PMid:3702944

23. Winter R.B, Banta J.V, Engler G. Screening for Scoliosis (Letter) JAMA 1995; 273:185 - 186

https://doi.org/10.1001/jama.273.3.185 PMid:7807649

24. Yasuo Y, Takuo Y, and Yoshiyuki A. Prediction of Curve Progression in Idiopathic Scoliosis based on Initial Roentgenograms. A Proposal of an Equation. Spine 1988; 13 (11): 1258 - 1261.

https://doi.org/10.1097/00007632-198811000-00009

25. Yim Annie P. Y, Yeung Hiu-Yan, Hung Vivian W. Y, Kwong-Man Lee, Tsz-Ping Lam, Yong Qiu, Jack C.

Y. Cheng. Abnormal Skeletal Growth Patterns in Adolescent Idiopathic Scoliosis. A Longitudinal Study until

Skeletal Maturity. Spine. 2012;37 (18):E1148-E1154

https://doi.org/10.1097/BRS.0b013e31825c036d PMid:22565390 